\title{
Effects on ocular discomfort and tear film dynamics of suturing 23-gauge pars plana vitrectomies
}

\author{
Efeito da sutura da vitrectomia via pars plana de calibre 23 no \\ desconforto ocular e na dinâmica do filme lacrimal
}

\author{
Jae Hoon Lee', Kyung Sun Na², Tai Kyong Kim³, Hea Young Oh', Mee Yon Lee' \\ 1. Department of Ophthalmology, Uijeoungbu St. Mary's Hospital, College of Medicine, The Catholic University of Korea, Gyeonggi-do, Korea. \\ 2. Department of Ophthalmology, Yeouido St. Mary's Hospital, College of Medicine, The Catholic University of Korea, Seoul, Korea. \\ 3. MokpoHanbit Eye Center, Mokpo, Korea.
}

\begin{abstract}
I Purpose: To evaluate the effects of suturing 23-gauge pars plana vitrectomies on ocular discomfort and tear film dynamics. Methods: This retrospective chart review involved data from 50 procedures in 50 patients who underwent 23-gauge pars plana vitrectomy from January to November 2016. We divided the eyes into two groups according to the presence or absence of sutures; 35 eyes underwent sutureless vitrectomies (Group 1), and 15 eyes underwent vitrectomy with at least one sclerotomy suture site (Group 2). In each group, we assessed objective variables including tear film break-up time, Schirmer test l, corneal surface grading with Oxford system, and a quantitative method evaluating subjective dry eye symptoms using ocular surface disease index questionnaires preoperatively 1 week, and 1 and 3 months after surgery. Results: The tear film break-up time showed a significant difference at the 3-months follow-up $(p=0.026)$. The Schirmer test $I$ and corneal surface staining score showed no statistically significant differences between two groups at any time after the operations. The ocular surface disease index score was significantly lower in Group 1 than in Group 2 at 1 week ( $p=0.032), 1$ month $(p=0.026)$, and 3 months $(p=0.041)$ after the operation. Conclusion: Sclerotomy suturing caused ocular discomfort and had a negative effect on tear film dynamics during the late postoperative period. Sclerotomies without suturing seem to reduce the ocular surface changes.
\end{abstract}

Keywords: Vitrectomy/methods; Dry eye syndrome; Tears/ physiology; Sclera/surgery

Submitted for publication: February 27, 2018

Accepted for publication: September 15, 2018

Funding: No specific financial support was available for this study.

Disclosure of potential conflicts of interest: None of the authors have any potential conflicts of interest to disclose.

Corresponding author: Mee Yon Lee.

Department of Ophthalmology, Uijeoungbu St. Mary's Hospital, College of Medicine, The Catholic University of Korea - 271 Cheonbo-ro, Uijeongbu-si, Gyeonggi-do 11765,

Korea - E-mail: deenie@daum.net

Approved by the following research ethics committee Uijeoungbu St. Mary's Hospital, College of Medicine, The Catholic University of Korea (\#UC17RESI0057).
RESUMO | Objetivo: Avaliar os efeitos da sutura da vitrectomia via pars plana de 23-gauge sobre o desconforto ocular e a dinâmica do filme lacrimal. Métodos: Esta revisão retrospectiva de prontuários envolveu dados de 50 casos em 50 pacientes submetidos à vitrectomia via pars plana de 23-gauge, de janeiro a novembro de 2016. Dividimos os olhos em dois grupos de acordo com a presença ou ausência de suturas; 35 olhos foram submetidos à vitrectomia sem sutura (Grupo 1) e 15 olhos foram submetidos à vitrectomia com pelo menos um ponto de sutura no local da esclerotomia (Grupo 2). Em cada grupo, avaliamos variáveis objetivas incluindo tempo de ruptura do filme lacrimal, teste de Schirmer l, gradação da superfície corneana com o sistema Oxford e um método quantitativo avaliando sintomas subjetivos de olho seco usando questionários de índice de doença da superfície ocular nos períodos: 1 semana do pré-operatório, 1 mês e 3 meses após a cirurgia. Resultados: $\mathrm{O}$ tempo de ruptura do filme lacrimal apresentou diferença significativa no seguimento de 3 meses $(p=0,026)$. O teste de Schirmer I e o escore da coloração da superfície da córnea não mostraram diferenças estatisticamente significativas entre os dois grupos em nenhum momento após as operações. O escore do índice de doença da superfície ocular foi significativamente menor no Grupo $1 \mathrm{em}$ relação ao Grupo 2 no período de 1 semana $(p=0,032), 1$ mês $(p=0,026)$ e 3 meses $(p=0,041)$ após a cirurgia. Conclusão: A sutura da esclerotomia causou desconforto ocular e teve um efeito negativo na dinâmica do filme lacrimal durante o período pós-operatório. Esclerotomias sem sutura parecem reduzir as alterações da superfície ocular.

Descritores: Vitrectomia/métodos; Síndrome do olho seco; Lágrimas/fisiologia; Esclera/cirurgia

\section{INTRODUCTION}

Patients often experience dry eye symptoms including eye irritations, foreign body sensation, and visual disturbance and complain of tear film dysfunction after undergoing vitrectomies. Larger incisions, longer procedures, and suturing in surgery create more postoperative discomfort and inflammation ${ }^{(1-4)}$. 
Microincision vitrectomy surgery using a 25-gauge instrument was first introduced in $2002^{(5)}$. It offered many advantages over the conventional 20-gauge system, including shorter operation times and reduced postoperative discomfort because of the minimal surgical trauma without the use of any sutures for sclerotomy. However, the 25-gauge instrument was excessively flexible and made peripheral vitreous dissection difficult, which limited its use to simple vitreoretinal diseases. Subsequently, 23-gauge vitrectomy was introduced to provide the advantages of smaller sutureless incisions combined with sturdier instruments to allow easier manipulation of the globe compared with the 25-gauge instruments ${ }^{(6)}$. However, sclerotomy sutures may still be required for silicone oil endotamponades, wound leakages, and postoperative hypotony ${ }^{(7,8)}$.

The ocular surface changes or the impact on dry eye after vitrectomy with or without sclerotomy site sutures have not been assessed. Although studies have focused on the disadvantages of suturing, the association between dry eye symptoms and sclerotomy site suturing has not been determined. This is the first study evaluating the effects of suturing after 23-gauge pars plana vitrectomy on ocular surface parameters and severity of subjective dry eye symptoms.

We assessed changes in objective tests including tear film break-up time (TBUT), Schirmer I test, corneal surface grading with the Oxford system, and the subjective ocular surface disease index (OSDI) questionnaire after 23-gauge vitrectomy with or without sclerotomy site suturing.

\section{METHODS}

We conducted this study in accordance with the regulations of the Institutional Review Board of Uijeoungbu St. Mary's Hospital, College of Medicine, the Catholic University of Korea (IRB \#UC17RESI0057). Investigator obligations and procedures conformed to the tenets of the Declaration of Helsinki.

\section{Patients and surgical procedures}

This retrospective chart review involved 50 cases from 50 patients who underwent 23-gauge pars plana vitrectomy combined with standard phacoemulsification from January to November 2016. A single experienced surgeon (M.Y. Lee) performed all surgeries at the Uijeoungbu St. Mary's Hospital. The 23-gauge sclerotomies (23-gauge TSV system; Alcon Laboratories, Fort
Worth, TX, USA) were performed with two-step tunnel transconjunctival incisions made using a 23-gauge stiletto blade at a $30^{\circ}$ angle parallel to the corneoscleral limbus to facilitate the insertion of the microcannulas. At the end of the procedure, the surgeon carefully removed the cannulas, gently massaged the sclerotomy sites with a cotton swab, and inspected the site for signs of leakage that might indicate the need for suture placement. If no leakage of the intraocular perfusate or gas was evident, the operation was completed without suturing (Group 1). If any leak was evident, the sclerotomies and conjunctiva had to be closed with one or two vicryl 8.0 suture (Group 2). All patients received topical treatment with eye drops (Loteprednol etabonate suspension $0.5 \%$, Lotemax ${ }^{\circledR}$; Bausch + Lomb, Tampa, FL, USA) and 0.5\% moxifloxacin (Vigamox ${ }^{\circledR}$; Alcon Laboratories). The eye drops were applied four times per day for at least 30 days postoperatively. We excluded data from patients with a history of previous ocular surgery or ocular injury, disorders of the nasolacrimal pathway, ocular allergies or blepharitis from the study. All patients underwent dry eye tests and completed the OSDI questionnaires. TBUT, Schirmer I test, determination of corneal staining score, and OSDI questionnaire assessments were completed preoperatively and at 1 week, 1 month, and 3 months after the operations. A single experienced ophthalmologist performed all examinations.

\section{Clinical evaluation}

TBUT

We used TBUT to assess the stability of the tear film. We instilled a $2 \%$ fluorescein solution in the medial conjunctival sac and measured the time until one or more dry spots appeared in the precorneal tear film from the last blink using a slit-lamp microscope.

\section{Schirmer I test}

We assessed the availability of tear fluid using the Schirmer I test without anesthesia. We bent the Schirmer strip (Eagle Vision, Memphis, TN, USA) at the notch and placed the strip at the inferior outer fornix. After 5 minutes, we removed the strip and measured the maximum wetting point.

\section{Corneal staining}

We used the corneal fluorescein staining to assess damage of the ocular surface by staining the cornea and observing it through a slit-lamp with cobalt blue 
illumination. The grading of staining was based on the National Eye Institute system ${ }^{(9)}$. We graded the amount of staining according to stain intensity with $0,1,2$, and 3 indicating respectively no staining, slight staining, moderate staining, and intense staining.

\section{Patient-reported symptom measures}

The OSDI questionnaire assesses the subjective ocular symptoms of dry eye disease ${ }^{(2)}$. We used a validated Korean version of the OSDI questionnaire that assesses three subscales of vision-related symptoms, ocular symptoms, and environmental triggers. Higher OSDI scores indicated more severe symptoms.

\section{Statistical analyses}

We used the SPSS version 15.0 software (SPSS, Chicago, IL, USA) for statistical analyses. All data are presented as the mean \pm the standard deviation. We used the Mann-Whitney U test for pairwise comparisons of group categorical variables and the Wilcoxon signed rank test to compare within-group categorical variable changes from the baseline. In addition, we used the Chi-square test to analyze baseline characteristics of the Patients. We considered all tests with p-values $<0.05$ as statistically significant.

\section{RESULTS}

We analyzed data from 50 eyes of 50 patients (31 men, 19 women). We divided the eyes into two groups according to the presence or absence of sutures. Group 1 included data from 35 eyes that underwent sutureless vitrectomies, and Group 2 included data from 15 eyes that underwent vitrectomies with at least one sclerotomy site suture. We found no significant difference in the ages of patients between the groups (Group 1, 70.13 \pm 9.27 years; Group $2,72.27 \pm 8.26$ years; $p=0.88$ ). Table 1 summarizes the baseline characteristics of the patients. The underlying conditions requiring vitreous surgery included macular holes in eight eyes, epiretinal membranes in 21 eyes, rhegmatogenous retinal detachments in four eyes, and vitreous hemorrhages in 17 eyes.

\section{TBUT}

The mean TBUTs in Group 1 were $12.18 \pm 2.54$ seconds before surgery, $7.35 \pm 2.21$ seconds 1 week after surgery, $9.51 \pm 2.91$ seconds at the 1-month follow-up, and $11.84 \pm 2.85$ seconds at the 3-month follow-up. The mean results in the Group 2 were $11.64 \pm 3.50$ seconds before surgery, $7.01 \pm 2.23$ seconds 1 week after surgery, $8.03 \pm 2.68$ seconds at the 1 -month follow-up, and $9.12 \pm 2.71$ seconds at the 3-month follow-up. We found no statistically significant differences between the two groups in terms of TBUTs at the 1-week and 1-month follow-ups ( $p=0.611$ and $p=0.175$, respectively), but the difference was significant at the 3-month follow-up $(p=0.026)$. The TBUTs showed statistically significant worsening at 1 week after surgery compared with before surgery in both Group 1 and Group 2 ( $p=0.008$ and $p=0.012$, respectively). However, 1 and 3 months after surgery, the TBUTs showed significant improvement in both groups (Group 1, p $=0.027$ at 1 month, and $p=0.045$ at 3 months; Group 2, $p=0.021$ at 1 month, and $p=0.031$ at 3 months) (Table 2).

\begin{tabular}{|c|c|c|c|}
\hline Total & Sutureless group & Suture group & p-value \\
\hline 50 & 35 & 15 & \\
\hline $71.88 \pm 10.12$ & $70.13 \pm 9.27$ & $72.27 \pm 8.26$ & $0.88^{*}$ \\
\hline & & & $0.31^{\dagger}$ \\
\hline 31 & 21 & 10 & \\
\hline 19 & 14 & 5 & \\
\hline 29 & 20 & 9 & \\
\hline 21 & 15 & 6 & \\
\hline & & & NA \\
\hline 8 & 5 & 3 & \\
\hline 21 & 15 & 6 & \\
\hline
\end{tabular}

*= determined by Mann-Whitney test; $\dagger=$ determined by Chi-square test. 
Table 2. Mean value of ocular surface parameters measured preoperatively, at 1 week, 1 month and 3 months after vitrectomy surgery

\begin{tabular}{|c|c|c|c|c|c|c|c|}
\hline & \multirow[b]{2}{*}{ Preop } & \multirow[b]{2}{*}{1 week postop } & \multirow[b]{2}{*}{1 month postop } & \multirow[b]{2}{*}{$\begin{array}{l}3 \text { months } \\
\text { postop }\end{array}$} & \multicolumn{3}{|c|}{$* P$-value } \\
\hline & & & & & $\begin{array}{c}\text { Preop vs. } 1 \\
\text { week postop }\end{array}$ & $\begin{array}{c}\text { Preop vs. } 1 \\
\text { month postop }\end{array}$ & $\begin{array}{c}\text { Preop vs. } 3 \\
\text { months postop }\end{array}$ \\
\hline \multicolumn{8}{|l|}{ TBUT (sec) } \\
\hline Group 1 & $12.18 \pm 2.54$ & $7.35 \pm 2.21$ & $9.51 \pm 2.91$ & $11.84 \pm 2.85$ & 0.008 & 0.027 & 0.045 \\
\hline Group 2 & $11.64 \pm 3.50$ & $7.01 \pm 2.23$ & $8.03 \pm 2.68$ & $9.12 \pm 2.71$ & 0.012 & 0.021 & 0.031 \\
\hline${ }^{\dagger} \mathrm{P}$-value & 0.508 & 0.611 & 0.175 & 0.026 & & & \\
\hline \multicolumn{8}{|c|}{ Schirmer test (mm) } \\
\hline Group 1 & $13.44 \pm 2.84$ & $12.84 \pm 2.23$ & $13.15 \pm 2.24$ & $13.23 \pm 2.56$ & 0.449 & 0.553 & 0.432 \\
\hline Group 2 & $13.82 \pm 2.07$ & $13.01 \pm 2.57$ & $13.44 \pm 2.31$ & $13.35 \pm 1.91$ & 0.441 & 0.532 & 0.441 \\
\hline${ }^{\dagger} \mathrm{P}$-value & 0.481 & 0.462 & 0.612 & 0.536 & & & \\
\hline \multicolumn{8}{|c|}{ Corneal staining score } \\
\hline Group 1 & $1.38 \pm 0.55$ & $1.68 \pm 0.42$ & $1.54 \pm 0.32$ & $1.52 \pm 0.61$ & 0.083 & 0.367 & 0.336 \\
\hline Group 2 & $1.36 \pm 0.50$ & $1.75 \pm 0.31$ & $1.55 \pm 0.58$ & $1.51 \pm 0.43$ & 0.092 & 0.246 & 0.221 \\
\hline${ }^{\dagger} \mathrm{P}$-value & 0.781 & 0.572 & 0.389 & 0.125 & & & \\
\hline \multicolumn{8}{|c|}{ Ocular symptom score } \\
\hline Group 1 & $19.18 \pm 2.94$ & $34.73 \pm 2.84$ & $24.36 \pm 2.29$ & $20.36 \pm 2.11$ & 0.012 & 0.021 & 0.039 \\
\hline Group 2 & $19.44 \pm 2.07$ & $41.06 \pm 2.90$ & $32.09 \pm 2.87$ & $24.34 \pm 2.99$ & 0.009 & 0.015 & 0.025 \\
\hline${ }^{\dagger} \mathrm{P}$-value & 0.841 & 0.032 & 0.026 & 0.041 & & & \\
\hline
\end{tabular}

Bolded values indicate statistical significance $(p<0.05)$.

* Wilcoxon Signed Rank test, †Mann-Whitney test to compare the changes between the two groups.

Preop $=$ preoperative; Postop $=$ postoperative .

\section{Schirmer I test}

The mean Schirmer I tests in Group 1 were $13.44 \pm$ $2.84 \mathrm{~mm}$ before surgery, $12.84 \pm 2.23 \mathrm{~mm} 1$ week after surgery, $13.15 \pm 2.24 \mathrm{~mm}$ at the 1-month follow-up, and $13.23 \pm 2.56 \mathrm{~mm}$ at the 3 -month follow-up. The results in Group 2 were $13.82 \pm 2.07 \mathrm{~mm}$ before surgery, 13.01 $\pm 2.57 \mathrm{~mm}$ at 1 week after surgery, $13.44 \pm 2.31 \mathrm{~mm}$ at the 1-month follow-up, and $13.35 \pm 1.91 \mathrm{~mm}$ at the 3-month follow-up. We found no statistically significant differences between the two groups at all postoperative time points (all $p>0.05$; Table 2).

\section{Corneal staining score}

The mean corneal staining scores in the Group 1 were $1.38 \pm 0.55$ before surgery, $1.68 \pm 0.421$ week after surgery, $1.54 \pm 0.32$ at the 1 -month follow-up, and 1.52 \pm 0.61 at the 3 -month follow-up. The results in Group 2 were $1.36 \pm 0.50$ before surgery, $1.75 \pm 0.311$ week after surgery, $1.55 \pm 0.58$ at the 1-month follow-up, and $1.51 \pm 0.43$ at the 3 -month follow-up. Corneal staining scores worsened 1 week postoperatively and recovered at 1 and 3 months in both groups, with no statistically significant differences between the groups at any postoperative time points (all $p>0.05$; Table 2 ).

\section{Ocular surface disease index questionnaire score}

The OSDI scores in Group 1 were $19.18 \pm 2.94$ before surgery, $34.73 \pm 2.841$ week after surgery, 24.36 \pm 2.29 at the 1 -month follow-up, and $20.36 \pm 2.11$ at the 3-months follow-up. The results in Group 2 were $19.44 \pm 2.07$ before surgery, $41.06 \pm 2.901$ week after surgery, $32.09 \pm 2.87$ at the 1-month follow-up, and $24.34 \pm 2.99$ at the 3 -months follow-up. The OSDI scores worsened 1 week postoperatively and recovered at 1 and 3 months in both groups. The OSDI scores were significantly lower in Group 1 than in Group 2 at the 1-week, 1-month, and 3-months follow-ups. We found statistically significant differences between the two groups in OSDI scores at 1 week, 1 month, and 3 months $(p=0.032, p=0.026, p=0.041$, respectively; Table 2$)$.

\section{DISCUSSION}

In our study, sclerotomy suturing affected the dry eye test and patients' symptoms. Dry eye symptoms got significantly worse during the entire postoperative period in the sclerotomy suturing group than in the non-suturing group. However, suturing adversely affected the TBUTs only during the late postoperative period with no significant differences on the postoperative 
Schirmer I test between groups. These findings suggest that the ocular discomfort that develops after suturing is the result of tear film instability rather than of decreased tear production.

Studies have shown that TBUT and the barrier function of the corneal epithelium are affected in the early postoperative period after cataract surgery ${ }^{(10,11)}$. Park et al. showed that TBUT was inversely correlated with interleukin (IL)-8, IL-1 $\beta$, IL-6, tumor necrosis factor-alpha, and interferon-gamma levels in lacrimal tears 1 month after cataract surgery ${ }^{(12)}$. But our results showed a significant difference evident only 3 months postoperatively. The reason for this difference in timing is the result of the presence of sclerotomy site suture during the operation in our patients. We suspect that suturing of the conjunctiva and capsule of tenon affects the recovery process by disrupting the goblet cells in the conjunctiva. Goblet cells, which primarily secrete mucin in the tear film, may decrease their mucin secretion leading to aggravated tear film instability ${ }^{(10,13,14)}$.

The recovery process of the ocular surface after vitrectomy involves wound healing similar to the cutaneous wound healing associated with complex and multi-organized processes ${ }^{(15,16)}$. Fujita et al. documented recovery of ocular surface molecules after transconjunctival pars plana vitrectomy ${ }^{(17)}$, which is consistent with our findings. The degree of elevation in the level of inflammatory cytokine IL-8 in tears was significantly lower after 23-gauge vitrectomy than after 20-gauge vitrectomy. Sclerotomy suturing can create mechanical stress that can lead to the production of IL-8. However, we suspect that the mechanical stress itself would not be sufficient and that it would likely cause effects together with cellular reactions during wound healing. No reports have focused on the effects of mechanical stress on the expression of chemical mediators after suturing. Thus, further studies are necessary to prove or refute this speculation. In addition, the inflammatory process is also promoted by the absorption of the vicryl 8.0 suture.

Exposure to light from the operating microscope may also be associated with postoperative tear film instability ${ }^{(10,18)}$. Although we observed that the sutureless group spent less time for wound closing than the suture group, the total operation duration did not show differences between the two groups. Therefore, the phototoxicity may have had little, if any, effects on the ocular discomfort and tear film dynamics in our study.

We had expected to see significant worsening in ocular symptom scores in the suture group compared with the scores in the sutureless group. The association between sense of discomfort or irritation and cytokine production has been studied for skin and ocular surfaces $^{(19,20)}$, and we suspected that suturing would induce direct foreign body sensation and discomfort.

The eye drop preservatives in Lotemax (Benzalkonium chloride) may alter the tear film; but in our study, we prescribed the same eye drops for patients in both groups during the same period, so no any effects would have been equivalent in both groups.

We are aware of the limitations of our study. First, its retrospective nature can limit data analysis and allow for inherent biases. Second, our sample size was small, and the heterogeneity on the number of cases in subgroups is another limitation of our study. These limitations should be kept in mind when interpreting the results. Prospective studies with larger sample sizes are needed. Also, evaluations of corneal sensitivity and molecular biological mechanisms should be addressed in future studies.

The incidence of sutureless vitrectomy has increased because of several well-known advantages including no postoperative suture-related astigmatism and reduced operation and rehabilitation times. The present data reveal that sutureless vitrectomy also limits the ocular surface changes.

\section{REFERENCES}

1. Wimpissinger B, Kellner L, Brannath W, Krepler K, Stolba U, Mihalics C, et al. 23-Gauge versus 20-gauge system for pars plana vitrectomy: a prospective randomised clinical trial. $\mathrm{Br}$ J Ophthalmol. 2008;92(11):1483-7.

2. Schiffman RM, Christianson MD, Jacobsen G, Hirsch JD, Reis BL. Reliability and validity of the Ocular Surface Disease Index. Arch Ophthalmol. 2000;118(5):615-21.

3. Kellner L, Wimpissinger B, Stolba U, Brannath W, Binder S. 25-gauge vs 20-gauge system for pars plana vitrectomy: a prospective randomised clinical trial. Br J Ophthalmol. 2007;91(7):945-8.

4. Shibata T, Watanabe A, Takashina H, Tsuneoka H. Effect on corneal shape of suturing the scleral wound during 23-gauge vitreous surgery. Jpn J Ophthalmol. 2012;56(5):441-4.

5. Fujii GY, De Juan E Jr, Humayun MS, Pieramici DJ, Chang TS, Awh $\mathrm{C}$, et al. A new 25-gauge instrument system for transconjunctival sutureless vitrectomy surgery. Ophthalmology. 2002;109(10):1807-12; discussion 1813. Erratum in: Ophthalmology. 2003;110(1):9.

6. Eckardt C. Transconjunctival sutureless 23-gauge vitrectomy. Retina. 2005;25(2):208-11.

7. Gramajo AL, Meyer M, Juárez CP, Luna JD. Long-term hypotony because of accidental break of a $23 \mathrm{~g}$ microcannula after transconjunctival sutureless vitrectomy. Retin Cases Brief Rep. 2014; 8(3):183-6.

8. Lin AL, Ghate DA, Robertson ZM, O'Sullivan PS, May WL, Chen C). Factors affecting wound leakage in 23-gauge sutureless pars plana vitrectomy. Retina. 2011 Jun;31(6):1101-8.

9. Lemp MA. Report of the National Eye Institute/Industry workshop on Clinical Trials in Dry Eyes. CLAO J. 1995;21(4):221-32. 
10. Li XM, Hu L, Hu J, Wang W. Investigation of dry eye disease and analysis of the pathogenic factors in patients after cataract surgery. Cornea. 2007;26(9 Suppl 1):S16-20.

11. Szakáts I, Sebestyén M, Tóth É, Purebl G. Dry eye symptoms, patient-reported visual functioning, and health anxiety influencing patient satisfaction after cataract surgery. Curr Eye Res. 2017; 42(6):832-6.

12. Park Y, Hwang HB, Kim HS. Observation of influence of cataract surgery on the ocular surface. PLoS One. 2016;11(10):e0152460.

13. De Paiva CS, Villarreal AL, Corrales RM, Rahman HT, Chang VY, Farley WJ, et al. Dry eye-induced conjunctival epithelial squamous metaplasia is modulated by interferon-gamma. Invest Ophthalmol Vis Sci. 2007;48(6):2553-60.

14. Li Q, Fu T, Yang J, Wang QL, Li ZE. Ocular surface changes after strabismus surgery with different incisions. Graefes Arch Clin Exp Ophthalmol. 2015;253(3):431-8.

15. Gillitzer R, Goebeler M. Chemokines in cutaneous wound healing. J Leukoc Biol. 2001;69(4):513-21.
16. Engelhardt E, Toksoy A, Goebeler M, Debus S, Bröcker EB, Gillitzer R. Chemokines IL-8, GROalpha, MCP-1, IP-10, and Mig are sequentially and differentially expressed during phase-specific infiltration of leukocyte subsets in human wound healing. Am J Pathol. 1998; 153(6):1849-60.

17. Fujita A, Uchino E, Otsuka H, Arimura N, Noda Y, Ishibashi T, et al. Ocular surface molecule after transconjunctival vitrectomy. $\mathrm{Br}$ J Ophthalmol. 2011;95(3):419-23.

18. Ipek T, Hanga MP, Hartwig A, Wolffsohn J, O’Donnell C. Dry eye following cataract surgery: the effect of light exposure using an in-vitro model. Cont Lens Anterior Eye. 2018;41(1):128-31.

19. Barton K, Monroy DC, Nava A, Pflugfelder SC. Inflammatory cytokines in the tears of patients with ocular rosacea. Ophthalmology. 1997;104(11):1868-74.

20. Lam H, Bleiden L, de Paiva CS, Farley W, Stern ME, Pflugfelder SC. Tear cytokine profiles in dysfunctional tear syndrome. Am J Ophthalmol. 2009;147(2):198-205. e1. 